\title{
Diversified Performance of the Graphic Design of the Zodiac Tiger
}

\author{
Yifan Wang ${ }^{1, *}$ Danyang Zhu ${ }^{1}$
}

\author{
${ }^{1}$ Wuhan Textile University, Wuhan, China \\ ${ }^{*}$ Corresponding author. Email: 571247610@qq.com
}

\begin{abstract}
Chinese zodiac culture is the most charming traditional folk culture. And human beings need to inherit and innovate. With the rapid development of the new era, people's life style and aesthetic appreciation are becoming more and more diversified. To present the ancient Chinese zodiac tiger culture with the method and form of graphic design can improve people's cognition of the Chinese traditional folk culture. This paper explores the expression form of creative design of Chinese zodiac tiger graphics from multiple angles of re-design, and deeply analyzes the innovation of its theoretical aspects. In the graphic design of Chinese zodiac tiger, it is necessary to fully consider the connotation of its traditional culture and pay attention to its external form. At the same time, it is required to enrich the visual design elements of zodiac tiger, and fully close to people's cultural aesthetics. Chinese traditional culture must be fully adapted to the development of The Times. During this process, it should not only pay attention to the cultural connotation of the Chinese Zodiac, but also fully pay attention to the external visual form. And the Chinese Zodiac should be applied in the field of art design, so that the contemporary zodiac graphic design can be integrated into people's daily life in a new form.
\end{abstract}

Keywords: Zodiac tiger, Graphic design, Form of expression, Artistic features.

\section{INTRODUCTION}

\subsection{Significance and Purpose of the Study}

The Chinese zodiac has a pivotal position and far-reaching influence in the traditional folk culture of China, and has a long history. It is made up of twelve kinds of animals, which are arranged in the order of rat, ox, tiger, rabbit, dragon, snake, horse, sheep, monkey, rooster, dog and pig. Zodiac culture contains rich national cultural connotations. As one of the 12 Zodiac animals, the image of the Zodiac tiger needs to be redesigned in combination with modern design methods to complete the innovation and upgrading of the image of the Zodiac tiger, so that the public can perceive the deep spiritual connotation of the zodiac graphics. The traditional zodiac tiger graph is also facing new challenges and opportunities. The reason is the lack of a set of theories and methods suitable for modern design. It is of great research value to explore the diversification of zodiac tiger graphic design and its expression form. The analysis and study of its diversified artistic expression can not only fully show the traditional cultural connotation, but also provide new ideas for designers. Taking the zodiac tiger as the main research target, this paper studies its important cultural value in the process of national culture inheritance in the past dynasties in China, so as to better apply it in the field of design. The main purpose is to make people feel the visual beauty of different zodiac cultures. At the same time, in order to develop the zodiac tiger culture and improve the way of thinking and artistic creation, human beings must first continue the unique meaning of the traditional Zodiac culture. Secondly, it is required to blend with modern art concepts to create a kind of creative graphics with both aesthetic value and spiritual sustenance.

\subsection{Research Methods}

This paper adopts a variety of research methods. First, the literature research method is used to collect and integrate the literature related to this paper, so as to provide theoretical guidance for this paper. Secondly, with the use of the method of comparison, this paper has made comparative 
analysis of the collected data, the zodiac tiger graphic design and application form. And a specific analysis is carried out on the zodiac tiger graphic design form and characteristics. The advantages and disadvantages are summarized. Finally, this paper classifies and summarizes the information.

\subsection{Research Innovation Points}

Chinese traditional zodiac patterns are characterized by complexity and simplicity. Most of the colors are Chinese traditional folk colors, and the colors are relatively bright, which makes it difficult to meet the aesthetic needs of people in today's society. There are many constraints in the comprehensive application of its graphic design in the field of art. This paper analyzes the cultural connotation, aesthetic characteristics and diversified forms of zodiac tiger, and the main purpose of this paper is to design creative zodiac tiger graphics with national cultural connotation. This paper specifically discusses the form and method of the zodiac tiger graphic design, so as to revitalize the traditional folk culture in theoretical research and creative design.

\section{CULTURAL CONNOTATION AND ARTISTIC CHARACTERISTICS OF ZODIAC TIGER}

\subsection{Cultural Expressions of the Zodiac Tiger}

The Chinese zodiac is used to record the year of birth of a person. The Chinese zodiac with the year of birth is called its own zodiac sign. The tiger is one of the twelve Chinese zodiac animals. Chinese Zodiac is a unique way of numbering the years, also known as the chronology, in which the 12 animals in the Zodiac are combined with the earthly branch. 12 years is a cycle. In addition, in the long historical culture, the Chinese zodiac has many auspicious and beautiful meanings, such as "richness, expensiveness, health, peace, blessing, emolument, longevity, happiness" and so on. These auspicious wishes and good blessings can inspire people to yearn for a better life and work hard to move forward. In ancient Chinese culture, the tiger was called the king of beasts. On the one hand, it is an important symbol of majesty and power, which could not be offended by people. It shows the characteristics of tiger's bravery, power and violence. On the other hand, the tiger also has the traditional auspicious cultural implication. In ancient times, the tiger was widely regarded as a sign of Yang, and people usually hung a picture of a tiger descending from the mountain in the hall or on the wall of their homes to ward off evil spirits. In ancient China, people also kept various customs of wearing tiger-head shoes and hats for children, and people hoped that children would grow up safely, healthily and happily.

\subsection{Artistic Features of the Zodiac Tiger}

The artistic characteristics of the zodiac tiger graphics mainly include the following three aspects: expression, symbol, decoration and so on. The expression forms mainly include plane and three-dimensional ways. The plane expression of the zodiac tiger is mainly two-dimensional space, and its two-dimensional form can be well combined with the zodiac pattern and used in other visual art carriers, such as New Year pictures, paper cuts, embroidery and other folk arts. The threedimensional form of zodiac tiger graphics is mainly manifested in three-dimensional space, such as ceramic, clay sculpture, wood carving and other forms of technology. The symbolic characteristic: zodiac tiger pattern not only contains the Chinese ancestors' pursuit of longevity and health concept, but also embodies the spiritual sustenance for future generations. Chinese zodiac tiger shows the technique of "expressing one's ambition by means of objects and expressing one's feelings by means of objects" vividly. Its unique symbolism reflects the worship of all ethnic groups in ancient China to the twelve zodiac animals and the expectation of good lifes.

\section{PRINCIPLES AND FORMS OF ZODIAC TIGER GRAPHIC DESIGN}

\subsection{Graphic Design Principles of Zodiac Tiger}

The traditional zodiac tiger graphics are quite complicated. If human beings want to apply it in the design, it needs to be simplified. Also, its graphics should be refined and summarized. The design principles of zodiac tiger graphics can be summarized as follows. First, the design principle of primary and secondary order is important. In the overall design, it especially emphasizes the difference between the primary and secondary orders. Also, the content should highlight the main body, so as to prevent the picture from being chaotic. A distinction should be made between the primary and secondary elements of the graphics, 
and the color, point-line-plane, auxiliary design elements, etc. are properly arranged and combined. The whole graphic visual picture is divided into several parts to highlight the theme. Second, it is necessary to pay attention to the design principle of unifying the style. Zodiac tiger graphic design should be unified and harmonious with the overall design style. Third, the design principles must be adapted to the development of The Times. The design concept of the zodiac tiger graphic needs to get rid of the old and bring forth the new, and the original traditional concept of the modern zodiac tiger graphic needs to be restructured, interpreted and optimized to make it bloom with new vitality.

\subsection{Diversified Expression Forms of Zodiac Tiger Graphic Design}

The diversified expression forms of zodiac tiger graphic design are important part of its design process. The traditional zodiac tiger pattern is deeply integrated with contemporary design, and a variety of expression forms are deeply analyzed and studied to design a new graphic, which makes the folk culture of zodiac re-glow. The main conclusions are as follows:

\subsubsection{Making Hard Things Simple}

In graphic design, the traditional Chinese zodiac tiger pattern is simplified, the main content is abstracted and summarized, and the complicated part is processed to highlight its features without lossing its interest and decoration, forming a highly generalized graph, which is easy to recognize and remember.

\subsubsection{Modification and Deformation}

Modification and deformation is a creative form of expression in modern graphic design. By thinking about how to modify and transform the zodiac tiger figure, the designer can show its image vividly through the representation methods such as deficiency and reality, density, level and size. At the same time, the designer should pay attention to the principle of appropriateness, so as to meet the requirements of formal beauty.

\subsubsection{Heteromorphic and Isomorphic Forms}

Heteromorphic and isomorphic forms of expression are widely used in graphic design. It is a clever combination of different graphics to form a new visual graphics. The way of expression of this graphic creativity is not simply to accumulate elements, but to show the main image from multiple angles and break through the constraints of the original image. Designing a very creative zodiac tiger graphics can bring great visual effect to the audience.

\subsubsection{Text Graphics}

Text graphics are based on text. Without changing the text connotation, the character strokes is converted into corresponding or associated graphics, and the visual effect of text is weakened to highlight the expressive force of the graphics. Through the creative idea, zodiac characters and graphics can be combined, and the font will be more lively and interesting. This kind of design style has the identification and the cultural nature extremely, contains both the broad and profound cultural foundation and has the unique design idea.

\subsubsection{Element Substitution}

Element substitution is a very creative way of expression in the graphic design of the zodiac tiger. In the design, the basic characteristics of the zodiac tiger graphics are retained and some of them are replaced with the same or similar elements. After the replacement, the connotation of the graphics is sublimated and new meaning is produced. The expression form of element replacement adds rich content and new meaning to the graphics, with the imagination and expressiveness.

\subsubsection{Aggregation Graphics}

Aggregation graphic is a new creative graphic that integrates the single or similar elements of the zodiac tiger repeatedly in the graphic design. The elements of the graphic can reflect the characteristics of the zodiac tiger image, making the graphic clearer. From less to more, the new elements will enhance the decoration and ornamental value of the zodiac graphics, so as to bring new visual expression.

\section{THE APPLICATION OF THE ZODIAC TIGER IN MODERN GRAPHIC DESIGN}

With the development of the times, the application of Chinese Zodiac tiger graphics in the field of contemporary graphic design is more and more common, and many design works embody the 
rule of formal beauty. After the redesign of the Chinese zodiac tiger graphics, it integrates the new concept of graphic design in form, and uses various expression forms, such as simplification, modification and deformation, heteromorphic and isomorphic forms, text graphics, element substitution and aggregation graphics, so as to endow modern graphic design works with new symbolic significance. For example, there are zodiac pendant, poster, illustration, stamp, cultural and creative products, font design and zodiac cartoon film and television, etc. Designers have also designed many creative designs with the theme of zodiac. Vacaliebres, an Italian designer, designed a series of zodiac graphic design works with the theme of twelve Zodiacs, as shown in "Figure 1". According to the traditional Zodiac image and the characteristics of the terrestrial branch, the designer abstracted the image of tiger head into a simple figure, which is mainly composed of round shape and water drop shape. The shape is very simple and vivid, showing the charm of Chinese traditional tiger head image and high recognition. The application of Chinese Zodiac tiger graphics in graphic design reflects the artistic vitality of traditional Chinese Zodiac tiger graphics, forming new visual symbols and glowing brilliantly in traditional culture. In the innovation and inheritance, it is necessary to integrate Chinese traditional Zodiac culture with modern aesthetic ideas and modern visual elements. Every audience can realize that the zodiac tiger graphic design is not only a simple innovation and upgrading, but also shows a new attitude to rejuvenate, making China's zodiac culture bright.

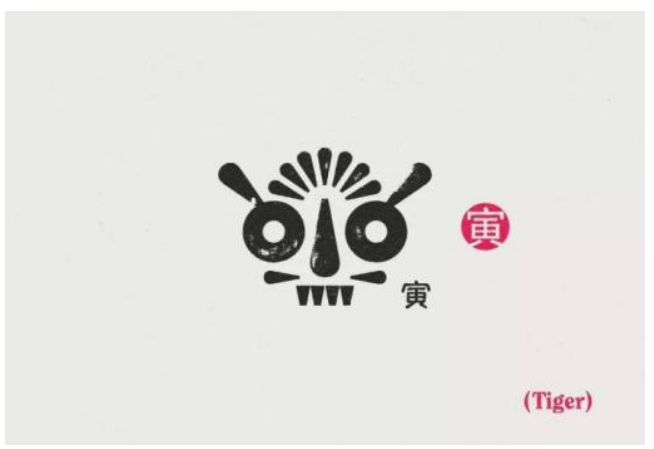

Figure 1 Chinese Zodiac tiger graphic

\section{PROSPECTS}

\subsection{The Development Potential of Chinese Zodiac Tiger Graphic Design}

Zodiac tiger graphic design has a profound cultural heritage. Whether now or the future, its market development potential is immeasurable. With the rapid development of economy, the development of graphics, digitalization and industrialization is becoming more and more rapid. At present, the academic research on the graphic design and application of the zodiac culture is still in an important stage of continuous in-depth exploration and research development, and the development prospect is good. The design research and promotion of the zodiac tiger graphic is imperative, and it also needs to be closely combined with the contemporary design concept. It is the main trend of art development in today's society to continue the development of creativity through the way of cultural communication. Using the zodiac graphic design to drive the development of other designs has great development potential. Chinese Zodiac tiger graphic design needs to have strong aesthetic interest, but also can be widely applied to people's daily life to show the characteristics and charm of China's traditional folk culture.

\subsection{Inheritance and Innovation of Tiger Graphic Design}

With the development of society and the change of life style, people's pursuit of spiritual level is also higher and higher. Now, more and more people choose to read pictures, which is a problem that human beings need to pay special attention to. How to revive the traditional Chinese Zodiac tiger culture needs all human beings to work together to effectively improve and solve this problem. This paper studies the graphic design of the Chinese Zodiac tiger at the height of cultural theory. Combining with modern design principles and methods, human beings can feel the beauty of China's traditional Chinese Zodiac culture with innovative ideas, design creative Chinese Zodiac tiger graphics to arouse people's attention to China's Chinese Zodiac culture, and create excellent design with national characteristics. This plays a key role and significance for the inheritance and innovation of Chinese folk culture.

\section{CONCLUSION}

The artistry and manifestation of the Chinese Zodiac tiger culture add a lot of new fun to modern people's daily life. This paper mainly studies and analyzes the various expression ways of the Chinese Zodiac tiger in graphic design, and focuses on the cross-border cooperation between traditional culture and modern art. While inheriting the 
traditional culture, human beings should constantly integrate more in line with the contemporary humanistic concept and modern art design concept, and blend the Chinese traditional Zodiac tiger and more traditional patterns with contemporary art. The re-creation of Chinese Zodiac graphics should not lose the local cultural characteristics, but also rise in the world's cultural and artistic trends. After the redesign of the zodiac tiger graphics, it is used as a new visual element in many design fields to complete the transformation and upgrading from folk culture to modern aesthetics. The innovation of the graphic design of the zodiac tiger will make the zodiac culture flourish, rooted in the culture of national characteristics, and lead the new design trend.

\section{REFERENCES}

[1] Zheng Jun. Zodiac Decoration Design [M]. Beijing: People's Fine Arts Publishing House, 2011. (in Chinese)

[2] Zhao Ruichun. Decorative graphics [M]. Shanghai: Shanghai People's Fine Arts Publishing House, 1994. (in Chinese)

[3] Zhang Yingie. Creative thinking and application of imagery and graphics $[\mathrm{M}]$. Beijing: Water Resources and Hydropower Press, 2011. (in Chinese)

[4] Liu Danlong, Wang Jiamin, Chen Peng. Research on the Cultural Features and Design of the Chinese Zodiac [J]. "New West (Second Half of the Month)". 2007.10. (in Chinese)

[5] [Russia] Kandinsky, Luo Shiping, Wei Dahai, Xin Li translation. Kandinsky's thesis line and surface [M]. Beijing: Renmin University of China Press, 2008. (in Chinese)

[6] Lu Shaofu. Graphic creative design [M]. Shanghai: Shanghai People's Fine Arts Publishing House, 2007. (in Chinese)

[7] Yin Dingbang. Figure and Meaning [M]. Changsha: Hunan Science and Technology Press, 1998. (in Chinese)

[8] Sun Rongfu. Chinese Zodiac and Good Fortune $[\mathrm{M}]$. Shanghai: Shanghai University Press, 2004. (in Chinese)

[9] Lan Xingjun. The exploration of the Chinese zodiac signs in print advertisements $[\mathrm{J}]$. Culture and Art Research, 2003, (52). (in Chinese)
[10] Lan Xingjun. Research on the Chinese Zodiac in Print Advertising [J]. Cultural and Art Research, 2013, (52). (in Chinese) 